\title{
Clinical Audit as a Quality Improvement Tool in Measurements of Lying and Standing Blood Pressure for Elderly Patients Admitted With a Hip Fracture
}

\author{
Isaac C. Okereke ${ }^{1}$, Kingsley Mmerem ${ }^{1}$, Mohamed Aly ${ }^{1}$ \\ 1. Trauma and Orthopaedics, The Royal London Hospital, London, GBR
}

Corresponding author: Isaac C. Okereke, okereke.isaac@gmail.com

\begin{abstract}
Background: Around one in three adults aged 65 years and over will have a fall at home within a one-year period. Falls are estimated to cost the NHS more than £2.3 billion per year. The National Institute for Health \& Care Excellence (NICE) guidelines recommend older people who present for medical attention because of a fall, report recurrent falls in the past year, or demonstrate abnormalities of gait and/or balance should be offered a multifactorial falls risk assessment which includes a cardiovascular examination and review of medications. Orthostatic hypotension $(\mathrm{OH})$ is a common cardiovascular disorder, independently associated with an increased risk of falls in the elderly.
\end{abstract}

Aims \& Objectives: This study was carried out to assess improvement in lying and standing blood pressure (LSBP) measurement using clinical audit and staff education.

Method: An initial audit of patients over the age of 60, admitted with a hip fracture between the 14th of April and the 25th of May 2020 to assess measurement and accurate recording of LSBP. This cycle was followed by brainstorming, root cause analysis, teaching sessions for staff, and use of aide-memoires. A second audit cycle of patients was admitted with a hip fracture secondary to a fall between the 10th of August and the 21st of September 2020.

Result: Our initial audit results showed $68 \%$ of patients who met the criteria in the NICE guidelines on measurement of LSBP were not being assessed for $\mathrm{OH}$. Following interventions, the second audit cycle showed significant improvement in compliance, confirming audits to be a powerful tool in quality improvement programs.

Review began 06/29/2021 Review ended 07/31/2021 Published 07/31/2021

\section{๑) Copyright 2021}

Okereke et al. This is an open access article distributed under the terms of the Creative Commons Attribution License CC-BY 4.0., which permits unrestricted use, distribution, and reproduction in any medium, provided the original author and source are credited.
Categories: Internal Medicine, Quality Improvement, Trauma

Keywords: orthostatic hypotension, quality improvement, clinical audit, staff education, blood pressure

\section{Introduction}

A fall is defined as an event that results in a person coming to rest inadvertently on the ground or other lower level [1]. Whilst not all falls are fatal, most falls cause significant injuries such as fragility fractures, functional impairment, longstanding pain, and intracranial bleeds in predisposed individuals.

The UK government's Public Health Outcomes Framework reports the rates of emergency hospital admissions due to falls in patients 65 years and over in the financial year 2018-2019 as 2,198 per 1000,000; an equivalent to 226,567 hospital admissions [2]. Around one in three adults aged 65 and over will have a fall at home within one year. The rate of falls increases dramatically in both sexes and within all races and ethnicities as people age [3]. The human cost of falling is unquantifiable and includes physical distress, pain, injury, loss of confidence, loss of independence and mortality. Falls are a public health concern estimated to cost the NHS more than $£ 2.3$ billion per year and have a negative impact on patients' quality of life [4]. Risk factors for falls include age, female gender, visual impairments, gait imbalance polypharmacy, and previous falls history.

In elderly patients, a fall may indicate an underlying medical problem such as a lower respiratory tract infection, a urinary tract infection, an acute exacerbation of chronic disease, or it may be due to the existence of orthostatic hypotension [5]. Up to $30 \%$ of falls can be prevented [6] by using a standardized multidisciplinary approach. The National Institute for Health \& Care Excellence (NICE) guidelines recommend older people who present for medical attention because of a fall, report recurrent falls in the past year, or demonstrate abnormalities of gait and balance be offered a multifactorial falls risk assessment which includes a cardiovascular examination and a review of their current medications by managing clinicians [7]. 
Orthostatic hypotension $(\mathrm{OH})$ is a common cardiovascular disorder in the elderly population due to agerelated autonomic dysfunction. It can present with or without signs of neurodegenerative disease and occurs due to a blunted response by the neurogenic adaptive mechanisms that recruit the sympathetic system to compensate for venous filling that ensues when standing upright from a recumbent position $[8,9]$. The prevalence of $\mathrm{OH}$ in the general population is about $6 \%$ and rises exponentially with age to a range of between $10 \%$ to $30 \%$ in older adults [10-13]. Risk factors for $\mathrm{OH}$ include age, adrenal

insufficiency, hypertension and use of antihypertensive drugs, smoking status, low body mass index (BMI), and diabetes $[14,15]$. $\mathrm{OH}$ is assessed by taking blood pressure measurements in the supine and upright positions (lying and standing blood pressure [LSBP]) and is confirmed by a persistent systolic/diastolic blood pressure drop $>20 / 10 \mathrm{mmHg}$ within three minutes of standing. Orthostatic hypotension is significantly positively associated with falls in older adults and increased morbidity and mortality [16,17].

Clinical audits and feedback are common quality improvement strategies that offer clinicians an opportunity to measure how clinical care is provided and to assess whether set clinical standards are being met [18]. Audits are a tool for identifying areas of clinical care that need improvement, thereby focusing on education, research and quality improvement strategies to improve patient care and outcomes [19]. They constitute one of the pillars of clinical governance and can be described by the "plan", "do", "study", "act" phases that characterise the audit cycle.

In this study, we hypothesized that the percentage of elderly patients admitted with a hip fracture following a fall who had their LSBP measurements assessed while on admission as outlined in NICE clinical guidelines [4] could be improved upon by clinical audits, staff education, and by the effective use of aide-memoires and clinical proformas.

\section{Materials And Methods}

Ethical approval was given by the Salisbury District Hospital NHS Ethics Committee (CA_2020/21/4372).

A prospective study of patients above the age of 60 years admitted with a hip fracture following a fall between April 14 and May 25, 2020, in the Orthopaedics department was carried out. Fifty (50) patients (76\% females) were included in this audit. The average age of patients was 83.4 years $(\mathrm{SD}=8.03)$. The average length of hospital stay was 10 days. The electronic online observation charts (POET) and patients' notes while on admission were reviewed regularly for LSBP measurements recorded. Patients' notes were requested from the records department after discharge for further review.

The NICE guidelines for managing falls in older people were the clinical standards against which this audit was tested [4]. The results of this audit were presented at the mortality meeting of the Geriatric medicine department, and after brainstorming sessions, the following action plan was agreed upon:

To increase awareness about $\mathrm{OH}$ on the wards using flyers and posters within the wards; To hold teaching sessions for ward staff on the standard procedure for measuring LSBP and immediately record this data onto the electronic database (POET) system; Re-assess compliance in three months.

Teaching sessions on the standard procedure for the measurement of LSBP as outlined in the Royal College of Physician's (RCP) Falls and Fragility Fracture Audit Programme (FFAP) 2017 guidance [6] were organized for all ward staff. Aide-memoires detailing the standard procedure for LSBP measurement and recording (Figures 1,2) were placed in strategic locations around the wards. 


\section{Cureus}

Measurement of lying and standing blood pressure as part of a multifactorial falls risk assessment

\section{Procedure:}

Identify if you are going to need assistance to stand the patient and simultaneously record a BP. Use a manual sphygmomanometer if possible and definitely if the automatic machine fails to record.

1. Explain procedure to the patient.

2. The first BP should be taken after lying for at least five minutes.

3. The second BP should be taken after standing in the first minute

4. A third BP should be taken after standing for three minutes

5. This recording can be repeated if the BP is still falling

6. Symptoms of dizziness, light-headedness, vagueness, pallor, visual disturbance, feelings of weakness and palpitations should be documented.

7. A positive result is:

a. A drop in systolic BP of $20 \mathrm{mmHg}$ or more (with or without symptoms)

b. A drop to below $90 \mathrm{mmHg}$ on standing even if the drop is less than $20 \mathrm{mmHg}$. (with or without symptoms)

c. A drop in diastolic BP of $10 \mathrm{mmHg}$ with symptoms (although clinically much less significant than a drop in systolic BP)

8. Advise patient of results and if the result is positive,

a. inform the medical and nursing team

b. take immediate actions to prevent falls and or unsteadiness.

9. In the instance of positive results, repeat regularly until resolved.

10. If symptoms change, repeat the test.

Note:

NICE Clinical Guideline 161 Falls in older people: assessing risk and prevention says that the following groups of inpatients should be regarded as being at risk of falling in hospital and should receive an individualised, multifactorial assessment:

- all patients aged 65 and

- patients aged 50 to 64 years who are judged by a clinician to be at higher risk of falling because of an underlying condition.

FIGURE 1: Measurement of orthostatic blood pressure. 


\section{Cureus}

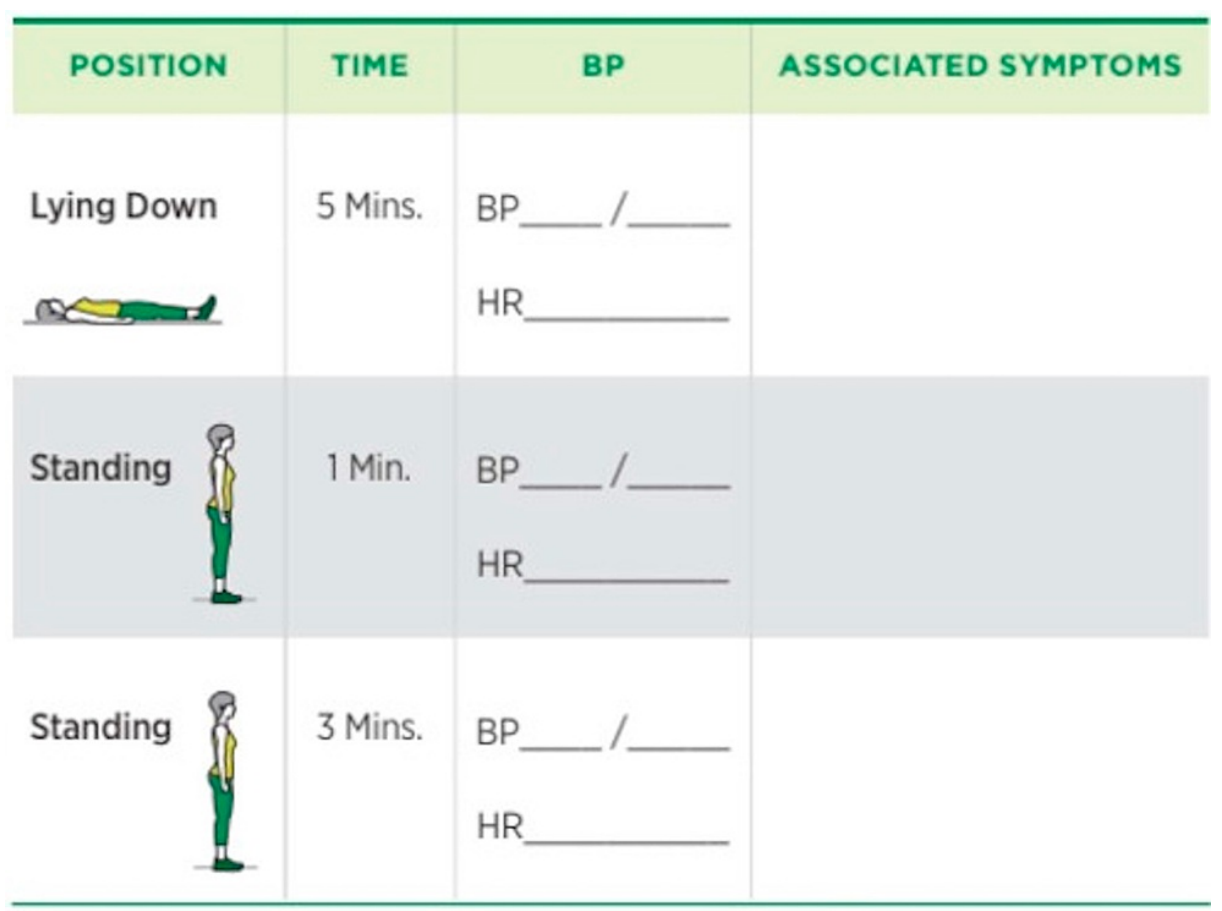

FIGURE 2: Documenting orthostatic blood pressure measurements

[21]

A retrospective audit of patients above the age of 60 , admitted with a hip fracture secondary to a fall between August 10 and September 21, 2020, in the Orthopaedics department was undertaken to assess progress and compliance with set standards. Fifty-eight (58) patients (73\% females) were included in this reaudit. The average age of patients was 81.4 years $(S D=7.05)$, and the average length of hospital stay was 11 days. All statistical analysis was performed using SPSS (version 25.0; IBM Corp., Armonk, NY, USA). The results of each audit were compared and statistically analyzed using the student's t-test to compare continuous variables and the chi-square test for discrete variables. A p-value of $<0.05$ was considered statistically significant.

\section{Results}

A total of 108 patients were reviewed over the two audit cycles. The common denominator was $>60$ years of age and admission to the Orthopaedics department following a fall. After the first audit, and following a root cause analysis, it was discovered that there was a lack of sufficient training amongst ward staff on the standard procedure for the accurate measurement and documentation of LSBP which led to poor compliance with set standards over time. Following the implementation of the action plan, the second audit showed a statistically significant improvement in both measurement and accurate documentation of LSBP values (Table 1).

\begin{tabular}{|c|c|c|c|}
\hline & First Audit $(n=50)$ & Second Audit $(n=58)$ & p value \\
\hline Gender m:f & $1: 3.16$ & $1: 2.62$ & $0.6715^{\star}$ \\
\hline Mean age (yrs) & $82.45 \pm 6.9$ & $81.4 \pm 7.05$ & $0.4375^{\star \star}$ \\
\hline LSBP measured & $16(32 \%)$ & $45(83.3 \%)$ & $<0.0001^{*}$ \\
\hline LSBP correctly documented & $12(75 \%)$ & $45(100 \%)$ & $0.0035^{\star \star \star}$ \\
\hline
\end{tabular}

\section{TABLE 1: Comparison of audit outcomes showing improvement}

${ }^{\star}$ Chi-square, ${ }^{\star \star} \mathrm{T}$-test, ${ }^{* \star *}$ Fischer exact test

LSBP: lying and standing blood pressure 


\section{Discussion}

This study attempted to show that clinical audit and implementation of staff education can be used as quality improvement tools for the accurate measurement and recording of LSBP in patients that are at high risk for falls.

A falls risk assessment consists of a falls history, medication review, physical examination, functional, and environmental assessments. Because the risk of falls increases with the presence of more risk factors, risk can be significantly reduced by modifying some of these factors. Longitudinal studies have shown a consistently positive association between $\mathrm{OH}$ and falls and have found $\mathrm{OH}$ to be causal rather than a consequence of falls [16]. OH, when symptomatic, can present as a feeling of light-headedness, dizziness, fatigue, altered mentation, blurred vision or syncope when standing from a recumbent position. It is the most common modifiable risk factor for falls in older people [22]. Causes of $\mathrm{OH}$ include drugs (antihypertensives, diuretics, peripheral vasodilators etc.), anaemia, sepsis, autonomic failure, carotid sinus disease and prolonged bed rest following an illness. Because not all patients who have $\mathrm{OH}$ are symptomatic, it should be searched for repeatedly in high-risk patients. The NICE Clinical Guideline for Falls in older people recommends that the following groups of inpatients should be regarded as being at risk of falling in hospital and should receive an individualized, multifactorial assessment: all patients aged 65 , and patients aged 50 to 64 years who a clinician judges to be at higher risk of falling because of an underlying condition.

Many patients who meet these criteria do not get their LSBP measurements correctly taken and recorded as indicated by the RCP, FFAP 2019-2021 document [20]. Even when done, there are inconsistencies in the procedural sequence and specific timing of BP measurements by ward staff. This can be attributed to a lack of proper clinical training on the practicalities involved in LSBP measurements, and a lack of awareness of set guidelines. In the first audit cycle, $68 \%$ of patients on the ward who were above the age of 60 and presented with a hip fracture following a fall were not assessed for OH. When LSBP was measured, it was wrongly recorded $25 \%$ of the time. Measuring LSBP is a complex procedure that is often impractical as patients are required to have been erect for a minimum of three minutes before erect blood pressure measurements are taken. Our root cause analysis after the first audit cycle identified poor staff training and the need for assistance when measuring LSBP (most patients require assistance of at least one person to stand erect post-operatively), as the main cause of non-compliance with set standards. Being conscious of the Hawthorne effect, where a subject alters their behaviour due to their awareness of being observed, teaching sessions explaining the physiology and pathology of $\mathrm{OH}$, coupled with instituting a system of constant feedback and reminders across all orthopaedic wards. The results of this were significant improvements in LSBP measurement and recording by ward staff by the next audit cycle.

Other strategies for falls prevention in the elderly are: an MDT approach to care, interventions that increase strength and balance such as the Otago exercise programme and community group classes, collaborating with patients and carers to effect behavioural change, reducing the chances of a fall injury by improving and optimising bone health through the use of calcium and vitamin D supplements, and the use of personal medical alerts in high-risk patients to prevent a long lie in the event of a fall [23,24].

There are several limitations of this study. We focused on the measurement or not of LSBP, hence, data on exact blood pressure recordings were not considered or analysed. Also, due to the variability in patients' post-operative recovery, the exact timing of LSBP measurement was not considered as some patients require more time to be mobilised when compared to others. Patients' records were however assessed throughout the duration of their in-hospital stay for LSBP recordings. Furthermore, improvements in LSBP measurement in high-risk patients recorded after the first audit may not be sustainable in the long term without constant staff education and feedback.

\section{Conclusions}

Orthostatic hypotension is common in hospitalized elderly patients and is a significant cause of falls in this age group. In this study, we showed that accurate measurements and recording of LSBP by ward staff improved significantly with teaching sessions and the use of clinical proformas thereby confirming audits to be a strong tool in clinical quality improvement. However, sustenance of these gains requires routine staff education and implementation of regular audit.

\section{Additional Information \\ Disclosures}

Human subjects: Consent was obtained or waived by all participants in this study. Salisbury District Hospital issued approval CA_2020/21/4372. Ethical approval was gotten from the Salisbury District Hospital Clinical audit committee. Animal subjects: All authors have confirmed that this study did not involve animal subjects or tissue. Conflicts of interest: In compliance with the ICMJE uniform disclosure form, all authors declare the following: Payment/services info: All authors have declared that no financial support was received from any organization for the submitted work. Financial relationships: All authors have declared that they have no financial relationships at present or within the previous three years with any organizations that might have an interest in the submitted work. Other relationships: All authors have 
declared that there are no other relationships or activities that could appear to have influenced the submitted work.

\section{References}

1. Falls. (2021). Accessed: May 8, 2021: https://www.who.int/news-room/fact-sheets/detail/falls.

2. Public Health Outcomes Framework: statistical commentary, February 2020 . (2021). Accessed: May 8, 2021: https://www.gov.uk/government/statistics/public-health-outcomes-framework-february-2020-dataupdate/public-health-out....

3. Pless IB: Falls in the elderly. Inj Prev. 1999, 5:2. 10.1136/ip.5.1.2-b

4. Falls in older people: assessing risk and prevention. (2013). Accessed: May 8, 2021: https://www.nice.org.uk/guidance/cg161/chapter/Introduction.

5. The Merck Manual of Geriatrics . Beers MH (ed): Merck \& Co., Inc., Kenilworth; 2001.

6. Royal College of Physicians 2016 National clinical guideline for stroke . (2017). Accessed: May 8, 2021: https://www.rcplondon.ac.uk/projects/outputs/measurement-lying-and-standing-blood-pressure-briefguide-clinical-staff.

7. Hip fracture: management. (2011). Accessed: May 5, 2021: https://www.nice.org.uk/guidance/cg124.

8. Ricci F, De Caterina R, Fedorowski A: Orthostatic hypotension: epidemiology, prognosis, and treatment . J Am Coll Cardiol. 2015, 66:848-60. 10.1016/j.jacc.2015.06.1084

9. Weiss A, Grossman E, Beloosesky Y, Grinblat J: Orthostatic hypotension in acute geriatric ward: is it a consistent finding?. Arch Intern Med. 2002, 162:2369-74. 10.1001/archinte.162.20.2369

10. Fedorowski A, Franceschini N, Brody J, et al.: Orthostatic hypotension and novel blood pressure-associated gene variants: Genetics of Postural Hemodynamics (GPH) Consortium. Eur Heart J. 2012, 33:2331-41. 10.1093/eurhearti/ehs058

11. Joseph A, Wanono R, Flamant M, Vidal-Petiot E: Orthostatic hypotension: a review . Nephrol Ther. 2017, 13 Suppl 1:S55-67. 10.1016/j.nephro.2017.01.003

12. Fedorowski A, Stavenow L, Hedblad B, Berglund G, Nilsson PM, Melander O: Consequences of orthostatic blood pressure variability in middle-aged men (The Malmö Preventive Project). J Hypertens. 2010, 28:551-9. 10.1097/HJH.0b013e3283350e8c

13. Wu JS, Yang YC, Lu FH, Wu CH, Chang CJ: Population-based study on the prevalence and correlates of orthostatic hypotension/hypertension and orthostatic dizziness. Hypertens Res. 2008, 31:897-904.

14. Fleg JL, Evans GW, Margolis KL, et al.: Orthostatic hypotension in the ACCORD (Action to Control Cardiovascular Risk in Diabetes) Blood Pressure Trial: prevalence, incidence, and prognostic significance. Hypertension. 2016, 68:888-95. 10.1161/HYPERTENSIONAHA.116.07474

15. Poon IO, Braun U: High prevalence of orthostatic hypotension and its correlation with potentially causative medications among elderly veterans. J Clin Pharm Ther. 2005, 30:173-8. 10.1111/j.1365-2710.2005.00629.x

16. Mol A, Bui Hoang PT, Sharmin S, Reijnierse EM, van Wezel RJ, Meskers CG, Maier AB: Orthostatic hypotension and falls in older adults: a systematic review and meta-analysis. J Am Med Dir Assoc. 2019, 20:589-97. 10.1016/j.jamda.2018.11.003

17. Fotherby MD, Iqbal P: Antihypertensive therapy and orthostatic responses in elderly hospital in-patients . I Hum Hypertens. 1997, 11:291-4.

18. Ray-Barruel G, Ullman AJ, Rickard CM, Cooke M: Clinical audits to improve critical care: part 2: analyse, benchmark and feedback. Aust Crit Care. 2018, 31:106-9. 10.1016/j.aucc.2017.04.002

19. Ullman AJ, Ray-Barruel G, Rickard CM, Cooke M: Clinical audits to improve critical care: part 1 prepare and collect data. Aust Crit Care. 2018, 31:101-5. 10.1016/j.aucc.2017.04.003

20. Royal College of Physicians Falls and Fragility Fracture Audit Programme Strategy: Improving Quality in Falls and Fragility Fracture Audit. (2019). http://www.rcplondon.ac.uk/projects/falls-and-fragility-fractureaudit-programme-fffap.

21. O'Riordan S, Vasilakis N, Hussain L, et al.: Measurement of lying and standing blood pressure in hospital . Nurs Older People. 2017, 8:20-26. 10.7748/nop.2017.e961

22. National Hip Fracture Database (NHFD). (2020). Accessed: May 5, 2021: https://www.rcplondon.ac.uk/projects/national-hip-fracture-database-nhfd.

23. Phelan EA, Mahoney JE, Voit JC, Stevens JA: Assessment and management of fall risk in primary care settings. Med Clin North Am. 2015, 99:281-93. 10.1016/j.mcna.2014.11.004

24. Campbell AJ, Robertson MC, Gardner MM, Norton RN, Tilyard MW, Buchner DM: Randomised controlled trial of a general practice programme of home based exercise to prevent falls in elderly women. BMJ. 1997, 315:1065-9. 10.1136/bmj.315.7115.1065 